\title{
The Synthesis of Unsymmetrical Diboron(5) Compounds and their Conversion to Diboron(5) Cations
}

\author{
Jessica Cid, Alexander Hermann, James E. Radcliffe, Liam D. Curless, Holger Braunschweig*, Michael \\ J. Ingleson* \\ School of Chemistry, The University of Manchester, Manchester M13 9PL, United Kingdom \\ Institute for Inorganic Chemistry, Julius-Maximilians-Universität Würzburg, Am Hubland, 97074 Würzburg, Germany \\ Institute for Sustainable Chemistry \& Catalysis with Boron, Julius-Maximilians-Universität Würzburg, Am Hubland, 97074 \\ Würzburg, Germany \\ Supporting Information Placeholder
}

\begin{abstract}
Reaction of bis-catecholatodiboron-NHC adducts, $\mathrm{B}_{2} \mathrm{Cat}_{2}(\mathrm{NHC}),(\mathrm{NHC}=\mathrm{IMe}$ (tetramethylimidazol-2-ylidene), IMes (1,3-dimesitylimidazol-2-ylidene) or IDIPP (1,3-bis(2,6-diisopropylphenyl)imidazol-2-ylidene)) with $\mathrm{BCl}_{3}$ results in the replacement of the catecholato group bound to the four coordinate boron with two chlorides to yield diboron(5) Lewis acid-base adducts of formula CatB-BCl $\left.\mathrm{Bl}_{2} \mathrm{NHC}\right)$. These compounds are precursors to diboron(5) monocations, accessed by adding $\mathrm{AlCl}_{3}$ or $\mathrm{K}\left[\mathrm{B}\left(\mathrm{C}_{6} \mathrm{~F}_{5}\right)_{4}\right]$ as halide abstraction agents in the presence of a Lewis base. The substitution of the chlorides of CatB- $\mathrm{BCl}_{2}(\mathrm{NHC})$ for hydrides is achieved

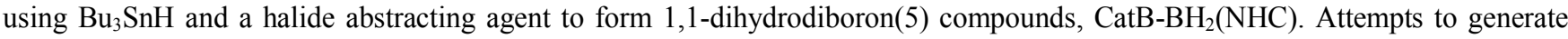
diboron(4) monocations of formula $[\mathrm{CatB}-\mathrm{B}(\mathrm{Y})(\mathrm{NHC})]^{+}(\mathrm{Y}=\mathrm{Cl}$ or $\mathrm{H})$ led to the rapid formation of CatBY.
\end{abstract}

\section{INTRODUCTION}

Organoboron complexes are ubiquitous reagents in synthesis due to their utility in many functional group transformations. Many modern routes to organoboranes use diboron(4) compounds, e.g. bis-pinacolatodiboron $\mathrm{B}_{2} \mathrm{pin}_{2}$, thus these reagents have received considerable interest - as have diboron(5) derivatives that possess two distinct boron moieties with one being four coordinate. ${ }^{1}$ These unsymmetrical diboron(5) species can be easily accessed by adding a neutral or anionic Lewis base to a $(\mathrm{RO})_{2} \mathrm{~B}-\mathrm{B}(\mathrm{OR})_{2}$ precursor, quaternizing one boron center. Quaternization leads to polarization of the $\mathrm{B}-\mathrm{B} \sigma$ bond and the resulting mixed $\mathrm{sp}^{2} / \mathrm{sp}^{3}$ diborons then react as sources of nucleophilic boron, reacting with an array of carbon electrophiles even in the absence of precious metal catalysts, thus providing a powerful route for forming C-B bonds. ${ }^{2}$

Until recently, the reactivity of diboron species as strong electrophiles had been mainly limited to highly reactive species such as $\mathrm{B}_{2} \mathrm{Cl}_{4}$. While $\mathrm{B}_{2} \mathrm{Cl}_{4}$ reacts with $\mathrm{H}_{2}$, diborylates alkynes, alkenes and aromatics, it decomposes above $0{ }^{\circ} \mathrm{C}$ and its use historically had also been limited by a complex synthesis. ${ }^{3}$ However, Braunschweig et al. has recently reported much simpler routes to $\mathrm{B}_{2} \mathrm{X}_{4}$ species. ${ }^{4}$ Other symmetrical diboron(4) compounds that have appreciable electrophilicity have also been recently reported (e.g. $\left.\mathrm{B}_{2}(p \text {-tolyl })_{4}\right)$ and shown to react with $\mathrm{H}_{2} .{ }^{5}$ In contrast, reports on the development of unsymmetrical diboron(4) and diboron(5) compounds that have significant electrophilicity are less common. Notable work in this area comes from Braunschweig et al., who during studies on the reactivity of Lewis bases with $\mathrm{R}(\mathrm{X}) \mathrm{B}-\mathrm{B}(\mathrm{X}) \mathrm{R}(\mathrm{X}=$ halide, $\mathrm{R}=$ mesityl (Mes), $t \mathrm{Bu}, \mathrm{NMe}_{2}$ ) synthesized an array of diboron(4)based borenium cations (A, Figure 1). ${ }^{6}$ More recently, Prokofjevs proposed the formation of a cationic $\mathrm{sp}^{2}-\mathrm{sp}^{3}$ diboron(5) cation formed from $\left[\left(\mathrm{L}-\mathrm{BH}_{2}\right)_{2}(\mu-\mathrm{H})\right]^{+}\left(\mathrm{L}=\mathrm{Me}_{3} \mathrm{CCH}_{2} \mathrm{NMe}_{2}\right)$, with calculations indicating that the diboron $(5)$ cation $\left[\mathrm{L}(\mathrm{H})_{2} \mathrm{~B}-\mathrm{BHL}\right]^{+}$is key in the intramolecular activation of aliphatic $\mathrm{C}-\mathrm{H}$ bonds. ${ }^{7}$ Other notable work in this area includes the formation an $\mathrm{sp}^{2}-\mathrm{sp}^{3}$ boryl-sub- stituted boronium salt $(\mathbf{B})^{8}$ (Figure 1) and the unsymmetrical diboron(4) compound pinBBMes $2(\mathbf{C})$, which reacts with $\mathrm{CO}$, isocyanides and pyridine. ${ }^{9}$ More recently, Wang and co-workers synthesized an $N$-heterocyclic carbene (NHC)-coordinated borylborenium cation (D), that when treated with $\mathrm{H}_{2}$ resulted in addition of $\mathrm{H}_{2}$ to the borenium center along with formation of Mes-BPin. ${ }^{10}$ In addition to small-molecule activation, Himmel and co-workers reported that diboron(5) monocations can also dimerize to generate an unusual $\mathrm{B}_{4}$ dication. ${ }^{11}$

These studies demonstrate that unsymmetrical diboron compounds are able to activate a range of small molecules in novel ways. However, the number of unsymmetrical and significantly electrophilic diboron compounds is still limited. Herein, we report the synthesis of readily available unsymmetrical diboron(5) compounds that can be converted to cationic diboron(5) species.

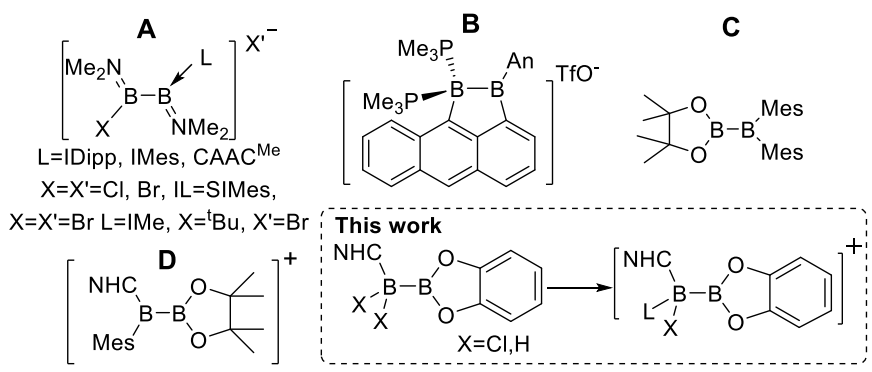

Figure 1. Structures of select previously reported unsymmetric electrophilic diboron (4) and diboron(5) compounds and inset, this work.

\section{RESULTS AND DISCUSSION}

Our previous work on the interaction of Lewis bases with diboron(4) compounds described the synthesis of the mono-NHC adduct $\mathrm{B}_{2} \mathrm{cat}_{2}(\mathrm{IMe})\left(\mathrm{IMe}=\right.$ tetramethylimidazol-2-ylidene). ${ }^{12}$ The re- 
action of $\mathrm{B}_{2} \mathrm{cat}_{2}(\mathrm{IMe})$, 1-IMe, with one equivalent of $\mathrm{BCl}_{3}$ in toluene at room temperature results in the formation of the new $\mathrm{sp}^{2}-\mathrm{sp}^{3}$ NHC adduct 2-IMe, which was isolated in $72 \%$ yield, with chlorocatecholborane observed as the side product (Scheme 1). The ${ }^{11} \mathrm{~B}$ NMR spectrum of 2-IMe reveals two resonances, one at 36.4 ppm (broad) for the $\mathrm{sp}^{2}-\mathrm{B}$ center and one at $-6.2 \mathrm{ppm}$ (sharp) for the $\mathrm{sp}^{3}$-B center. The same methodology was applied to synthesize the IMes and IDipp derivatives (2-IMes and 2-IDipp, respectively, IMes = 1,3-dimesitylimidazol-2-ylidene, IDipp = 1,3-bis(2,6-diisopropylphenyl)imidazol-2-ylidene) in good yields (77 and 81\%), with the ${ }^{11} \mathrm{~B}$ NMR spectra of both compounds being very similar to that observed for 2-IMe. It should be noted that analogous chemistry can be performed with $\mathrm{BBr}_{3},{ }^{14}$ however, attempts using other boron Lewis acids such as $\mathrm{BPh}_{3}, \mathrm{~B}\left(\mathrm{C}_{6} \mathrm{~F}_{5}\right)_{3}$ or $\mathrm{L}-\mathrm{BH}_{3}$ resulted in either no reaction or produced intractable products with no analogues of 2-IMe isolable.
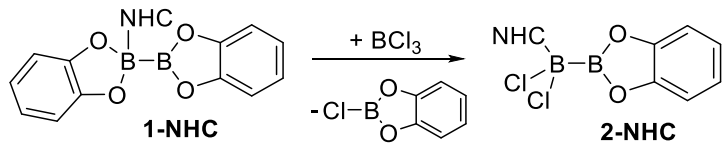

$\mathrm{NHC}=\mathrm{IMe}, \mathrm{IMes}, \mathrm{IDipp}$

\section{Scheme 1. Reaction of 1-NHC with $\mathrm{BCl}_{3}$ to give 2-NHC.}

Single crystals of 2-IMe suitable for X-ray crystallography were obtained by dissolution in ortho-dichlorobenzene (o-DCB) and layering with pentane. This confirmed the formulation, with the structure containing one four-coordinate boron and one threecoordinate trigonal planar (angles sum to 359.7) boron center. The B-B bond length in 2-IMe is in the range 1.683(8) to 1.699(8) $\AA$ (four inequivalent molecules of 2-IMe are present in the asymmetric unit) which is slightly shorter than in compound 1-IMe $(1.729(3) \AA)$ and $\mathrm{B}_{2}$ pin $_{2}-\mathrm{NHC}$ adducts reported previously $\left(\mathrm{B}_{2} \mathrm{pin}_{2}-\right.$ $\mathrm{NHC}$ adduct $=1.743(2)$ and $1.730(3) \AA)^{13}$. The B-C distance (1.630(7) $\AA$ ) does not differ significantly from its 1-IMe precursor (1.647(2) $\AA$ ) (Figure 2).

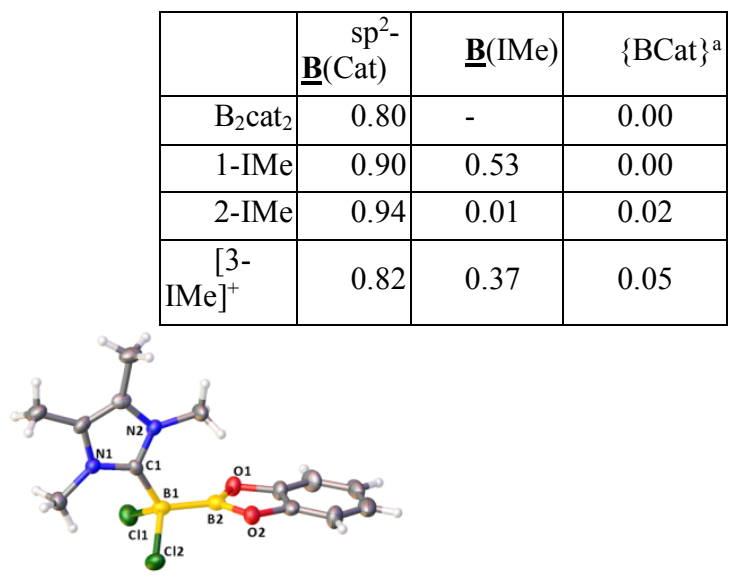

Figure 2. Solid state structure of 2-IMe. Ellipsoids are shown at the $50 \%$ probability level. Selected bond lengths (in $\AA$ ) and angles (in ${ }^{\circ}$ ): B1-B2 1.686(8), B1-C1 1.629(8), Cl1-B1-C12 108.3(3), Cl1-B1-C1 108.1(4), Cl2-B1-C1 105.3(4). Right, NBO charges calculated at the M06-2X/6-311G(d,p) level, $\mathrm{a}=\{\mathrm{BCat}\}$ refers to the overall charge on the $\mathrm{BCat}$ unit containing the three-coordinate boron center.

Compound $\mathbf{2}$ may be formed by a process involving either (i) a $\mathrm{B}-\mathrm{B}$ cleavage step, where transfer of a nucleophilic $\{\mathrm{BCat}\}^{-}$moiety from 1-NHC to $\mathrm{BCl}_{3}$ occurs followed by chloride transfer from $\left[\mathrm{CatB}-\mathrm{BCl}_{3}\right]^{-}$to a $[\mathrm{CatB}(\mathrm{NHC})]^{+}$cation and subsequent $\mathrm{NHC}$ transfer; or, (ii) interaction of $\mathrm{BCl}_{3}$ with the oxygen atom of a catechol group, leading to $\mathrm{B}-\mathrm{O} / \mathrm{B}-\mathrm{Cl}$ substituent exchange, but no $\mathrm{B}-$ $\mathrm{B}$ cleavage. To obtain a feasible mechanism for the formation of 2-
NHC, we performed a DFT study on the initial steps of the reaction. Calculations were carried out at the M06-2X/6-311G(d,p) level with a DCM polarizable continuum medium (PCM) solvation model. Despite extensive searching we were not able to locate any pathway involving the $\mathrm{CatB}-\mathrm{sp}^{2}$ unit reacting as a nucleophile to $\mathrm{BCl}_{3}$ to form $\left[\mathrm{CatBBCl}_{3}\right]^{-}$and $[\mathrm{CatB}(\mathrm{NHC})]^{+}$. Analysis of the charge distribution by NBO calculations (Figure 2, right) showed that in 1-IMe the $\mathrm{B} \mathrm{sp}{ }^{2}$ atom remains positively charged, meanwhile the $\mathrm{B} \mathrm{sp}{ }^{3}$ atom gains electron density (relative to that in $\mathrm{B}_{2} \mathrm{Cat}_{2}$ ) and overall this is similar to the charge distribution calculated previously for $\mathrm{B}_{2}$ pin $_{2}$ (IMes). ${ }^{15}$ Notably, the overall charge on the entire $\mathrm{sp}^{2}$-BCat unit is effectively zero in 1-IMe, which is distinct to that found for alkoxide-activated diboron(4) compounds (where the $\mathrm{sp}^{2} \mathrm{~B}(\mathrm{OR})_{2}$ center is overall partially negatively charged). Thus as previously observed, ${ }^{15} \mathrm{NHC}$ activation of diboron compounds results in the formation of a less nucleophilic $\mathrm{sp}^{2}$ $\mathrm{B}(\mathrm{OR})_{2}$ group than that formed by activation with alkoxide. ${ }^{15}$ For the second possible mechanism, Scheme 2 shows the calculated relative electronic and total energies of the different calculated intermediates for the first $\mathrm{O} / \mathrm{Cl}$ exchange. Starting from compound 1IMe, coordination of $\mathrm{BCl}_{3}$ to an oxygen atom of the two different catechol units gives two different intermediates $\mathbf{1 a}$ and $\mathbf{1 b}$. The difference in electronic energy between them is $19.1 \mathrm{kcal} / \mathrm{mol}$, with the more stable intermediate being that with $\mathrm{BCl}_{3}$ coordinated to the catechol bound to the B-sp ${ }^{3}$ center (1a), as expected. From this intermediate, a transfer of chloride from the $\mathrm{BCl}_{3}$ unit to the boron center occurs through $\mathbf{T S}_{1 \mathrm{a}-1 \mathbf{c}}$ with a relatively low energy barrier of $4.6 \mathrm{kcal} / \mathrm{mol}$. This results in the formation of intermediate 1c, containing a $\mathrm{ROBCl}_{2}$ moiety, which is slightly less stable than $\mathbf{1 a}$. From here, a second oxygen/chloride transfer would give compound 2-IMe and CatBCl.

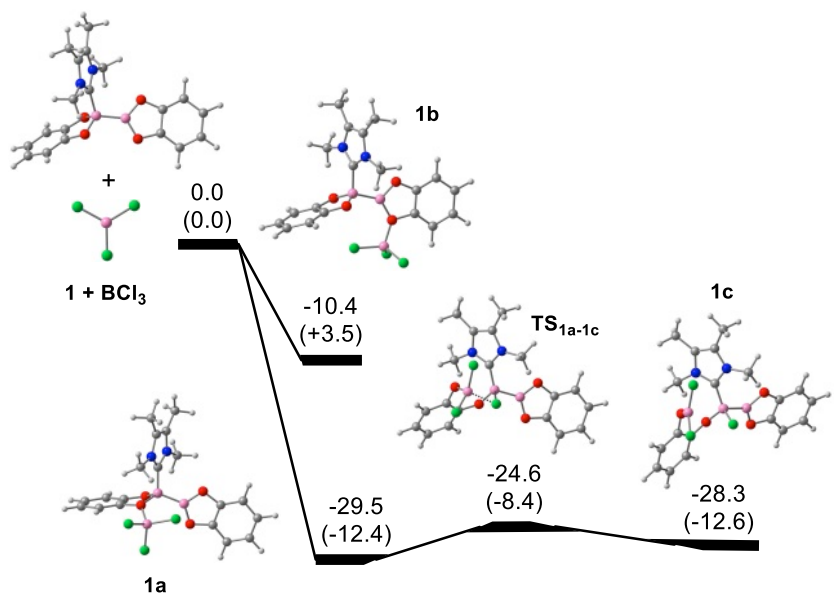

Scheme 2. Calculated energy profile for the possible initial steps of the B-O cleavage mechanism. Electronic and Gibbs free energies (in parenthesis) in $\mathrm{kcal} / \mathrm{mol}$.

Before investigating the synthesis of diboron(4) monocations derived from 2-NHC, calculations were performed to probe the charge distribution (using the NBO model), frontier orbital energy and Lewis acidity. The change of catecholato for two chlorides decreases the positive charge on the $\mathrm{B}(\mathrm{IMe})$ center in 2-IMe relative to 1-IMe, consistent with a lower degree of $\mathrm{B}-\mathrm{Cl}$ sigma bond polarization (charge on $\mathrm{Cl}=-0.3$ ) relative to $\mathrm{B}-\mathrm{O}$ (charge on $\mathrm{O}=-$ 0.8 ). The polarization of the $\mathrm{B}-\mathrm{B}$ bond is effectively unchanged on $\mathrm{OR}$ for $\mathrm{Cl}$ exchange as indicated by the overall charge on the entire $\{B C a t\}$ unit remaining effectively zero. In [3-IMe $]^{+}$the removal of chloride to generate the unit positive charge does not significantly alter the overall charge on the $\{\mathrm{BCat}\}$ unit. Instead, the unit positive charge is localized on the B-IMe moiety, despite the effectively co-planar arrangement of the $\mathrm{C}-\mathrm{B}-\mathrm{Cl}$ and $\mathrm{O}-\mathrm{B}-\mathrm{O}$ moieties. In the $\mathrm{B}$-IMe unit the boron center carries the largest degree of positive 
charge, as would be expected based on its more electropositive nature. The HOMOs for 2-IMe and [3-IMe] ${ }^{+}$(figure 3) were found to be very similar in character while the LUMOs are slightly more distinct, with more boron character present in the LUMO of [3IMe $]^{+}$. As expected, the relative LUMO energies indicate that compound 2-IMe is a weak Lewis acid while the diboron(4) monocation, [3-IMe $]^{+}$, is a stronger Lewis acid. This is supported by calculation of the chloride-ion affinity (CIA) of [3-IMe $]^{+}$relative to $\mathrm{AlCl}_{3}$, which was estimated using an approach based on the energy change for the transfer of chloride from $\left[\mathrm{AlCl}_{4}\right]^{-}$to the borenium cation (Figure 3, bottom). This value gives insight into the accessibility of the borenium cation by halide abstraction. The calculated CIA for [3-IMe] ${ }^{+}$is $12.3 \mathrm{kcal} / \mathrm{mol}$ (at the $\mathrm{B}-\mathrm{Cl}(\mathrm{IMe})$ centre) relative to $\mathrm{AlCl}_{3}$, which is comparable with previously synthesized borenium cations of type $\left[(\text { amine }) \mathrm{BCl}_{2}\right]^{+},{ }^{16}$ and thus indicates the feasibility of halide abstraction from 2-IMe using Lewis acids such as $\mathrm{AlCl}_{3}$.

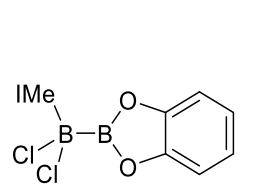

2-IMe

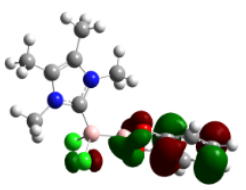

$\mathrm{HOMO}=-7.90 \mathrm{eV}$

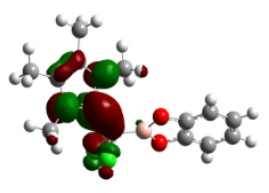

$\mathrm{LUMO}=0.24 \mathrm{eV}$

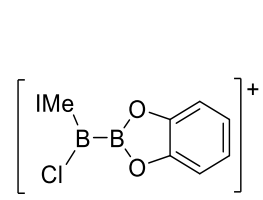

[3-IMe $]^{+}$

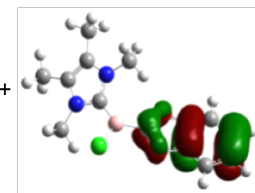

$\mathrm{HOMO}=-8.76 \mathrm{eV}$

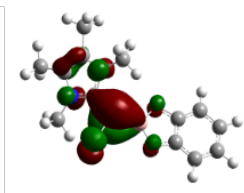

LUMO $=-2.87 \mathrm{eV}$

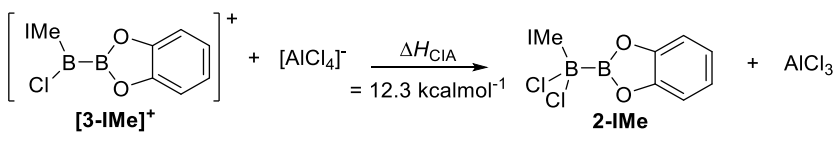

Figure 3. HOMO and LUMO representations for 2-IMe and [3IMe $]^{+}$at an isosurface value of 0.04 . Bottom, the relative (to $\mathrm{AlCl}_{3}$ ) chloride ion affinity of [3-IMe $]^{+}$.

Compound 2-IMe was reacted with $\mathrm{AlCl}_{3}$ using a range of conditions (temperature, solvent) and this led to the complete consumption of 2-IMe and formation of $\left[\mathrm{AlCl}_{4}\right]^{-}$(by multinuclear NMR spectroscopy). However, in the ${ }^{11} \mathrm{~B}$ NMR spectrum, we were only able to identify $\mathrm{BCl}_{3}$ (minor) and $\mathrm{CatBCl}$ (major) as products of this reaction. No intermediates were observed, and similar outcomes were achieved using other halide abstracting agents, e.g. $\mathrm{K}\left[\mathrm{B}\left(\mathrm{C}_{6} \mathrm{~F}_{5}\right)_{4}\right]$ and $\mathrm{NaBAr}{ }^{\mathrm{Cl}}\left(\mathrm{BAr}{ }_{4} \mathrm{Cl}_{4}=\left[\mathrm{B}\left(3,5-\mathrm{Cl}_{2}-\mathrm{C}_{6} \mathrm{H}_{3}\right)_{4}\right]^{-}\right)$with Cat$\mathrm{BCl}$ observed formed on reaction of 2-IMe with each of these salts. The formation of $\mathrm{CatBCl}$ from 2-IMe/ $\mathrm{AlCl}_{3}$ also occurs in chlorobenzene, indicating that the halide in $\mathrm{CatBCl}$ is unlikely to derive from the solvent. The results of the reaction of 2-IMes and 2-IDIPP with $\mathrm{AlCl}_{3}$ and $\mathrm{K}\left[\mathrm{B}\left(\mathrm{C}_{6} \mathrm{~F}_{5}\right)_{4}\right]$ did not lead to any identifiable or isolable species in our hands.

Attempts to trap the putative cation $\left[3-\mathrm{IMe}^{+}\right.$by performing halide abstraction in the presence of a range of small molecules (e.g. $\mathrm{H}_{2}, \mathrm{CO}$, terminal and internal alkynes) still produced $\mathrm{CatBCl}$ along with other intractable products. Therefore, attempts to trap the putative cation by adding better nucleophiles, specifically phosphine and amine Lewis bases, were explored. It should be noted that 2-IMe shows no reaction with the phosphines and amines used in this study in the absence of exogenous Lewis acid (by multinuclear NMR spectroscopy), consistent with the low Lewis acidity of 2-IMe indicated by calculations. The reaction of 2-IMe with $\mathrm{AlCl}_{3}$ in the presence of one equivalent of $\mathrm{PPh}_{3}$ results in the formation of the Lewis base-stabilized diboron(5)-monocation 4 (Figure 4). The ${ }^{11} \mathrm{~B}$ NMR spectrum of 4 shows two resonances, one for the $\mathrm{sp}^{2}$ boron atom at $37.7 \mathrm{ppm}$ and one for the $\mathrm{sp}^{3}$ boron atom at -14.8 ppm. The ${ }^{31} \mathrm{P}\left\{{ }^{1} \mathrm{H}\right\}$ NMR spectrum of $\mathbf{4}$ shows one broad signal at $1.44 \mathrm{ppm}$. The structure of $\mathbf{4}$ was confirmed by X-ray diffraction (Figure $4 \mathrm{~b}$ ) which confirmed the presence of an $\mathrm{sp}^{3} \mathrm{~B}$ and an $\mathrm{sp}^{2} \mathrm{~B}$ center. The B-B bond length in $\mathbf{4}$ was 1.717(8) $\AA$, which is longer than that in 2-IMe but shorter than Wang's diboron(5) (1.754(11) Å) monocation (PinB-B(NHC)(4-DMAP)Mes, the 4-DMAP adduct of compound D). ${ }^{10}$ The P-B distance in 4 (1.970(6) $\AA$ ) is consistent with that found in other phosphine-containing boronium cations. ${ }^{1 \mathrm{lb}}$ The addition of a second equivalent of $\mathrm{AlCl}_{3}$ to $4 \mathrm{did}$ not abstract the second chloride, with resonances for the cationic portion of 4 unchanged.

When 2-IMe was treated with one equivalent of 2-DMAP and one equivalent of $\mathrm{K}\left[\mathrm{B}\left(\mathrm{C}_{6} \mathrm{~F}_{5}\right)_{4}\right]$ in $o$-DCB, the ${ }^{11} \mathrm{~B}$ NMR spectrum of the reaction mixture indicated conversion to a new boron-containing product containing both $\mathrm{sp}^{2}$ and $\mathrm{sp}^{3}$ boron centers, $\delta_{11 \mathrm{~B}}=$ 29.9 and $-3.7 \mathrm{ppm}$, respectively. Crystals were isolated from the reaction mixture after layering with pentane. The structure of 5 confirms the formation of a diboron monocation of formula [CatB$\mathrm{B}(\mathrm{IMe}) \mathrm{Cl}(2-\mathrm{DMAP})]\left[\mathrm{B}\left(\mathrm{C}_{6} \mathrm{~F}_{5}\right)_{4}\right]$. While the $\mathrm{B}-\mathrm{B}$ distance of $1.711(5) \AA$ is very similar to that in 4 , the presence of the pendant $\mathrm{NMe}_{2}$ group has a noticeable structural effect. The $\mathrm{NMe}_{2}$ group of 2-DMAP is orientated towards the boron center of the BCat moiety with a B-N distance of $2.056 \AA$, suggesting a weak interaction between the $\mathrm{NMe}_{2}$ group and the $\mathrm{sp}^{2}$-B center. Consistent with a weak interaction between $\mathrm{N}$ and $\mathrm{B}$ is the small deviation from planarity of the BCat moiety (sum of angles $=354.3^{\circ}$ ). The distinct $\delta_{11 \mathrm{~B}}$ chemical shift of the $\mathrm{sp}^{2} \mathrm{~B}$ centre in $\mathbf{5}$ relative to $\mathbf{4}$ (29.9 and 37.7 ppm, respectively) suggests that this interaction persists in solution.
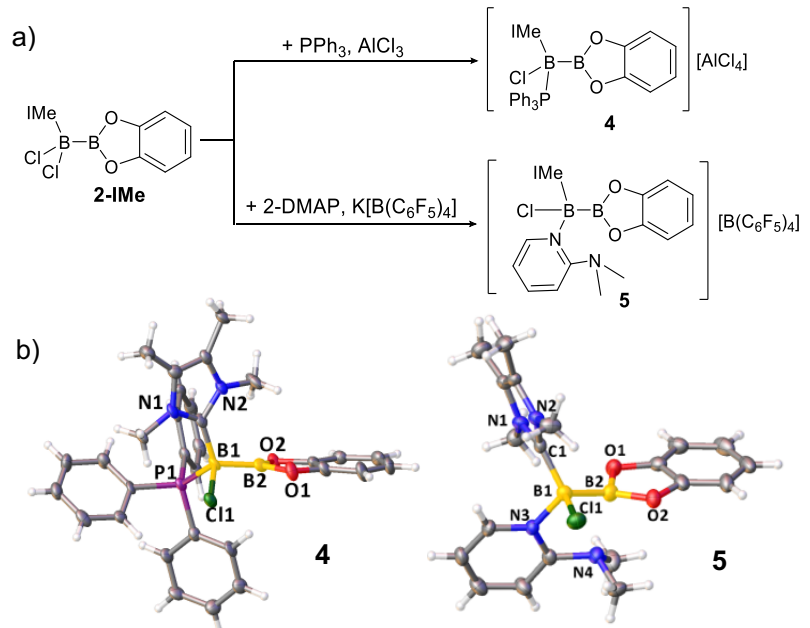

Figure 4. a) Synthesis of diboron-monocations 4 and 5. b) X-Ray crystal structures of $\mathbf{4}$ and $\mathbf{5}$. Selected bond lengths in $\AA$ : $\mathbf{4}$ : B1-B2 1.717(8), B1-C1 1.621(7), B1-P1 1.970(6); 5: B1-B2 1.711(5), B1C1 1.629(4), B1-N3 1.600(4).

Attempts to abstract the remaining chloride from 5 upon addition of $\mathrm{K}\left[\mathrm{B}\left(\mathrm{C}_{6} \mathrm{~F}_{5}\right)_{4}\right]$ or by reacting 2-IMe with 2-DMAP and excess $\mathrm{AlCl}_{3}$ failed (with 5 persisting by multinuclear NMR spectroscopy). The relative (to $\mathrm{AlCl}_{3}$ ) chloride ion affinity of the putative diboron(4) dication derived from chloride abstraction from $\mathbf{5}$ (and before binding of $\mathrm{NMe}_{2}$, Scheme 3) was calculated and found to be $-1.2 \mathrm{kcal} / \mathrm{mol}$, consistent with the lack of chloride abstraction using $\mathrm{AlCl}_{3}$. The LUMO energy of compound $5(-1.93 \mathrm{eV})$ is much higher than for [3-IMe] ${ }^{+}$, suggesting it is a weaker Lewis acid, and consistent with this, compound $\mathbf{5}$ did not react with alkynes such as 3-hexyne.

$$
\left[{ }_{\mathrm{IMe}^{\prime}}^{\mathrm{B}-\mathrm{B}_{\mathrm{O}}^{\prime}}\right.
$$

Scheme 3: The CIA of the dication derived from 5 
Due to the instability of putative [3-IMe $]^{+}$, our next target was exchanging a chloride group for an alternative substituent that is also amenable to abstraction using common reagents, specifically the 1,1-dihydrodiboron congener of 2-IMe. While reaction of 2IMe with silanes such as $\mathrm{HSiEt}_{3}$ or $\mathrm{HSiPh}_{3}$ gave complex mixtures of products that were intractable in our hands, the reaction of 2IMe with $10 \mathrm{~mol} \%$ of $\mathrm{Na}\left[\mathrm{BAr}_{4}\right]$ and two equivalents of $\mathrm{Bu}_{3} \mathrm{SnH}$ resulted in the rapid formation of the 1,1-dihydrodiboron derivative CatB-B(H) $)_{2} \mathrm{IMe}$, 6-IMe, within minutes. The ${ }^{11} \mathrm{~B}$ NMR spectrum of the reaction mixture containing 6-IMe shows a broad signal at $42.9 \mathrm{ppm}$ corresponding to the $\mathrm{sp}^{2}-\mathrm{B}$ and a broad singlet at -40.1 ppm corresponding to the dihydroborane (Figure 5), which is similar to similar compounds reported previously. ${ }^{17}$ Presumably, halide abstraction to form the [3-IMe] ${ }^{+}$cation facilitates hydride transfer from $\mathrm{Bu}_{3} \mathrm{SnH}$, as in the absence of $\mathrm{NaBAr}_{4} \mathrm{Cl}_{4}$ the reaction is extremely slow and yields multiple products. $\mathrm{Bu}_{3} \mathrm{Sn}-\mathrm{Cl}$ is observed as the expected tin byproduct from this reaction (and the ${ }^{11} \mathrm{~B}$ resonance for $\left[\mathrm{BAr}^{\mathrm{Cl}}{ }_{4}\right]$ persists). In the reaction mixture, compound 6IMe proved to be thermally sensitive, with the ${ }^{11} \mathrm{~B}$ NMR spectrum after $5 \mathrm{~min}$ at room temperature showing some decomposition, as indicated by the appearance of a quartet at $-36.6 \mathrm{ppm}(J=84.1 \mathrm{~Hz})$ that corresponds to $\mathrm{BH}_{3}$-IMe. ${ }^{18}$ The other product(s) that must form alongside $\mathrm{IMe}-\mathrm{BH}_{3}$ proved intractable and were not able to be identified in our hands. The purification of compound 6-IMe from $\mathrm{M}\left[\mathrm{BAr}_{4}{ }_{4}\right]\left(\mathrm{M}=\right.$ ?), $\mathrm{Bu}_{3} \mathrm{SnCl}$ and the decomposition products was also not successful in our hands.

The accessibility of the cation derived from 6-IMe initially was explored by calculation of the hydride ion affinity of [7-IMe $]^{+}$, which was found to be $-52.7 \mathrm{kcal} / \mathrm{mol}$ relative to $\mathrm{BEt}_{3}$ (Figure 5 , top). ${ }^{16}$ This suggests that the putative $\left[7-\mathrm{IMe}^{+}\right.$is less Lewis acidic toward hydride than $\mathrm{Ph}_{3} \mathrm{C}^{+}$but more so than $\mathrm{B}\left(\mathrm{C}_{6} \mathrm{~F}_{5}\right)_{3} .{ }^{19}$ The hydride ion affinity of 7-IMe is in fact comparable to other borenium cations (e.g. E, $-47.8 \mathrm{kcal} / \mathrm{mol}) .{ }^{16}$ Inspection of the frontier molecular orbitals revealed that the LUMO of [7-IMe $]^{+}$was found to be lower in energy than its precursor $(6-\mathrm{IMe}-0.39 \mathrm{eV} \text {; [7-IMe }]^{+}-$ $2.63 \mathrm{eV}$ ) and was mainly located on the B-IMe group. In contrast, the LUMO of 6-IMe was located mainly on the Bcat moiety. The LUMOs of the two cations $[7-\mathrm{IMe}]^{+}$and $[3-\mathbf{I M e}]^{+}$are similar in both character and energy. a)

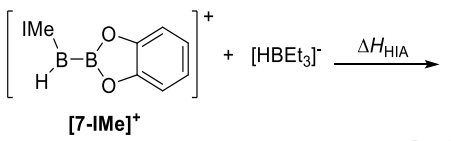

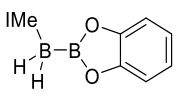

6-IMe

b)

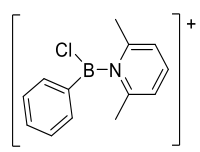

c)

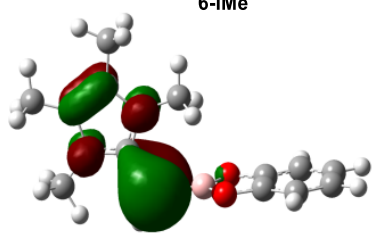

Figure 5. a) Isodesmic reaction used to calculate HIA. b) Borenium cation $E$ that possesses a similar HIA. c) LUMO representation of [7-IMe] ${ }^{+}$(isosurface value of 0.04 ).

Attempts were made to form [7-IMe ${ }^{+}$directly from the crude reaction mixture derived from 2-IMe / $\mathrm{M}\left[\mathrm{BAr}_{4}{ }_{4}\right] / \mathrm{Bu}_{3} \mathrm{SnH}$. The addition of trityl salts to this reaction mixture in haloarene solvents resulted in formation of $\mathrm{Ph}_{3} \mathrm{CH}$, however the only identifiable new boron containing species was $\mathrm{CatBH}$. CatBH is not derived from solvent activation, as CatBH is also formed when hydride abstraction is repeated in $\mathrm{d}_{5}$-bromobenzene, therefore the decomposition pathway of putative $[7-\mathrm{IMe}]^{+}$, which forms CatBH (and unidentified by-products), appears to be comparable to that for [3-IMe] ${ }^{+}$ which forms $\mathrm{CatBCl}$ and unidentified by-products. Seeking to trap the putative [7-IMe] ${ }^{+}$using competent nucleophiles, the mixture containing 6-IMe $(<2$ minutes after its formation) was reacted with a number of phosphine / $\mathrm{B}\left(\mathrm{C}_{6} \mathrm{~F}_{5}\right)_{3}$ frustrated Lewis pairs. The addition of $\mathrm{P}^{t} \mathrm{Bu}_{3}$ and $\mathrm{B}\left(\mathrm{C}_{6} \mathrm{~F}_{5}\right)_{3}$ gave the best result, producing a single major new boron compound with its ${ }^{11} \mathrm{~B}$ NMR spectrum showing a resonance at $39.2 \mathrm{ppm}$ attributed to the $\mathrm{B}$ of the $\mathrm{BCat}$ moiety, one at -37.2 attributed to the $\mathrm{BH}$ and one doublet at $-25.8 \mathrm{ppm}$ which is consistent with $\mathrm{HB}\left(\mathrm{C}_{6} \mathrm{~F}_{5}\right)_{3}$. However, the ${ }^{31} \mathrm{P}\left\{{ }^{1} \mathrm{H}\right\}$ NMR spectrum revealed several products and we were not able to isolate any of the desired unsymmetrical diboron(5) cations derived from 6IMe despite multiple attempts.

In order to increase the stability of the B-H diboron species, IMe was replaced with IMes and IDipp. Using the same procedure (addition of $10 \mathrm{~mol} \%$ of $\mathrm{Na}\left[\mathrm{BAr}^{\mathrm{Cl}}{ }_{4}\right]$ and two equivalents of $\left.\mathrm{Bu}_{3} \mathrm{SnH}\right)$, we were able to synthesize the corresponding 1,1-dihydro-diboron(5) compound for both NHCs, termed 6-IMes and 6IDipp. However, the isolation of 6-IMes and 6-IDipp was not possible to achieve since $\mathrm{Na}\left[\mathrm{BAr}^{\mathrm{Cl}}\right.$ ] co-crystallized with both species and could not be separated in our hands. Nevertheless, the ${ }^{11} \mathrm{~B}$ NMR spectrum of 6-IMes shows similar resonances to that observed for 6-IMe, including a broad signal at $42.4 \mathrm{ppm}$ and a broad signal at $-40.0 \mathrm{ppm}$, which supports the formation of 6-IMes. The solid-state structure of compound 6-IMes, crystallized by slow evaporation of a saturated solution in DCM, further confirmed the formulation of this series of compounds (Figure 6). The B-B bond distance in 6-IMes at 1.686(4) $\AA$ is slightly shorter than those displayed by Braunschweig et al. (1.702(6) $\AA$ ) for a related dihydrodiboron(5) but comparable to the B-B distance in 2-IMe. ${ }^{13}$ In all these compounds, the B-H coupling is not clearly resolved, which was also the case for other 1,1-dihydroboranes. ${ }^{17}$

a)

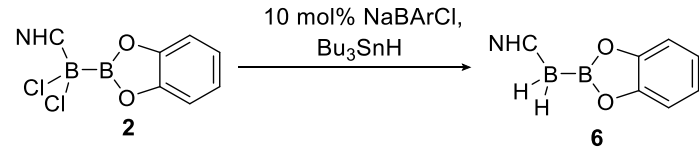

$\mathrm{NHC}=$ IMe, IMes, IDipp

b)

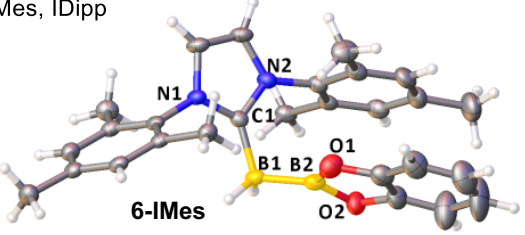

Figure 6. a) Synthesis of 1,1-dihydrodiboron(5) compounds b) Solid state structure of 6-IMe, ellipsoids at $50 \%$ probability. Selected bond lengths in Å: B1-B2 1.686(4), B1-C1 1.605(3).

Compounds 6-IMes and 6-IDIPP proved to be more thermally stable in solution, and formation of the hydrodiboron monocations [7-NHC] ${ }^{+}$was explored. The reaction of 6-IMes or 6-IDIPP (containing $\mathrm{Na}\left[\mathrm{BAr}{ }_{4}^{\mathrm{Cl}}\right]$ impurity) with $\left[\mathrm{Ph}_{3} \mathrm{C}\right]\left[\mathrm{B}\left(\mathrm{C}_{6} \mathrm{~F}_{5}\right)_{4}\right]$ again led to decomposition, with CatBH again observed at $27.8 \mathrm{ppm}(J=210$ $\mathrm{Hz}$ ) as one of the products in the ${ }^{11} \mathrm{~B}$ NMR spectrum. Attempts to form a Lewis base-stabilized hydrodiboron(4) monocation with these compounds using phosphine/ $\mathrm{B}\left(\mathrm{C}_{6} \mathrm{~F}_{5}\right)_{3}$ FLPs gave complex mixtures that proved intractable in our hands. Attempts to assess the reactivity of the putative cations $\left[7-\mathrm{NHC}^{+}\right.$by performing hydride abstraction from 6-NHC in the presence of alkynes also led to complex mixtures.

The decomposition of the putative diboron(4) cations to form $\mathrm{CatBCl}$ and $\mathrm{CatBH}$ appears to be a common reaction pathway. The disparity between the stability of $\left[3-\mathbf{N H C}^{+} /\left[7-\mathrm{NHC}^{+}\right.\right.$and Wang's closely related compound $\mathbf{C}$ is noteworthy and is presumably due to the superior $\pi$ donor properties of pinacol versus catechol, and the greater steric bulk of the Mes group (relative to $\mathrm{H}$ or $\mathrm{Cl}$ ). However, it should be noted that with compound $\mathbf{C}$, related B$\mathrm{B}$ bond cleavage reactions occur, leading to the formation of MesBPin (Scheme 4, bottom). 

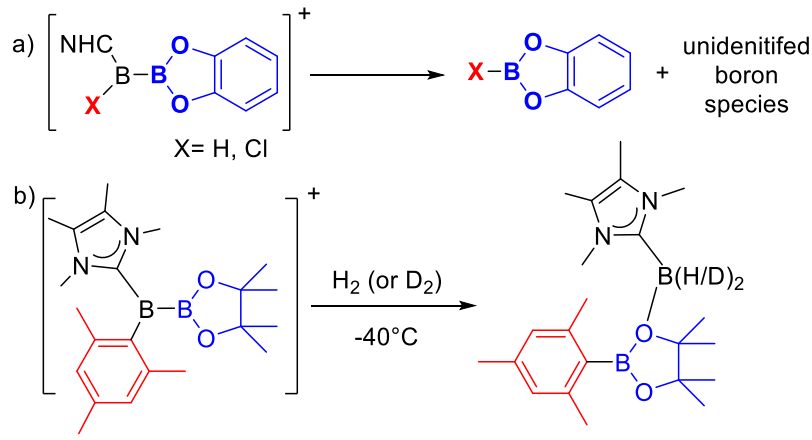

Scheme 4. a) Possible reaction pathway for the decomposition of $[3-\mathrm{NHC}]^{+}$and $\left[7-\mathrm{NHC}^{+}\right.$. b) Reaction of Wang's borylborenium with $\mathrm{H}_{2}$ or $\mathrm{D}_{2}$.

\section{CONCLUSIONS}

In this work we have reported the synthesis of NHCcoordinated diboron compounds 2-NHC. When the IMe congener of these diboron(5) compounds was treated with a Lewis base and $\mathrm{AlCl}_{3}$ or $\mathrm{K}\left[\mathrm{B}\left(\mathrm{C}_{6} \mathrm{~F}_{5}\right)_{4}\right]$, formation of Lewis base-stabilized di-boron(5) monocations proceeded. However, in the absence of competent nucleophiles, the putative diboron(4) monocation [CatB$\mathrm{B}(\mathrm{NHC}) \mathrm{Cl}]^{+}$reacted to form $\mathrm{CatBCl}$ and other unidentified boron containing species. The reaction of 2-NHC with $10 \mathrm{~mol} \%$ of $\mathrm{Na}\left[\mathrm{BAr}_{4}{ }_{4}\right]$ and two equivalents of $\mathrm{Bu}_{3} \mathrm{SnH}$ provides access to a series of 1,1-dihydrodiboron (5) compounds. However, it was not possible to achieve the synthesis and isolation of the putative [7IMe $]^{+}$cation derived from hydride abstraction due to its instability, with CatBH observed to form rapidly. Thus, there appears to be a minimum steric and electronic stabilization requirement to afford access to diboron(4) monocations.

\section{EXPERIMENTAL SECTION}

All appropriate manipulations were performed using standard Schlenk techniques or in an argon-filled MBraun glovebox $\left(\mathrm{O}_{2} / \mathrm{H}_{2} \mathrm{O}\right.$ levels below $0.5 \mathrm{ppm}$ ). Glassware was dried in a hot oven overnight and heated under vacuum before use. Solvents and amines were distilled from $\mathrm{NaK}, \mathrm{CaH}_{2}$, or $\mathrm{K}$ and degassed prior to use. Unless otherwise stated all compounds were purchased from commercial sources and used as received. NMR spectra were recorded on Bruker AvanceIII-400 or Bruker Ascend-400 spectrometers. Chemical shifts are reported as dimensionless $\delta$ values and are frequency referenced relative to residual protio impurities in the NMR solvents for ${ }^{1} \mathrm{H}$ and ${ }^{13} \mathrm{C}\left\{{ }^{1} \mathrm{H}\right\}$ respectively, while ${ }^{11} \mathrm{~B},{ }^{19} \mathrm{~F},{ }^{31} \mathrm{P},{ }^{27} \mathrm{Al}$ shifts are referenced relative to external $\mathrm{BF}_{3}-\mathrm{Et}_{2} \mathrm{O}$, hexafluorobenzene, $85 \%$ phosphoric acid and $\mathrm{Al}\left(\mathrm{NO}_{3}\right)_{3}$ in $\mathrm{D}_{2} \mathrm{O}\left(\mathrm{Al}\left(\mathrm{D}_{2} \mathrm{O}\right)_{6}{ }^{3+}\right)$, respectively. Coupling constants $\mathrm{J}$ are given in Hertz $(\mathrm{Hz})$ as positive values regardless of their real individual signs. The multiplicities of the signals are indicated as "s", "d", " $t$ " " q" "pent", "sept" or "m" for singlet, doublet, triplet, quartet, pentet, septet or multiplet, respectively. Unless otherwise stated all NMR spectra are recorded at $293 \mathrm{~K}$. Carbon atoms directly bonded to boron are not always observed in the ${ }^{13} \mathrm{C}\left\{{ }^{1} \mathrm{H}\right\}$ NMR spectra due to quadrupolar relaxation leading to signal broadening. All calculations were conducted at the M06-2X/6-311G(d,p) level with a solvation model (PCM, $\mathrm{CH}_{2} \mathrm{Cl}_{2}$ ) using the Gaussian software package. ${ }^{20}$ All geometry optimizations were full, with no restrictions. All stationary points located in the potential energy hypersurface were characterized as minima or transition states by vibrational analysis. Transition states had one and only one imaginary frequency, whose normal mode corresponded to the expected motion.

CatBBCl $\mathrm{IMe}_{2}$ (2-IMe). $\mathrm{BCl}_{3} 1 \mathrm{M}$ in hexanes $(2.42 \mathrm{mmol}, 2.42 \mathrm{~mL})$ was added to a stirred solution of $\mathrm{B}_{2} \mathrm{cat}_{2} \mathrm{IMe}$ (1-IMe) $(2.42 \mathrm{mmol}, 876$ $\mathrm{mg}$ ) in $20 \mathrm{~mL}$ of toluene at $-77^{\circ} \mathrm{C}$. After the addition, the reaction mixture was warmed to room temperature and was stirred for $2 \mathrm{~h}$. Afterwards, all volatiles were removed in vacuo. The residue was washed three times with pentane to yield a white solid $(786 \mathrm{mg}, 72 \%)$. Elemental analysis calc.: $\mathrm{C}_{13} \mathrm{H}_{16} \mathrm{~B}_{2} \mathrm{Cl}_{2} \mathrm{~N}_{2} \mathrm{O}_{2}$ : $\mathrm{C}, 48.07 ; \mathrm{H}, 4.97 ; \mathrm{N}, 8.62$.
Found: C, 48.23; $\mathrm{H}, 4.82 ; \mathrm{N}, 8.51 .{ }^{1} \mathrm{H}$ NMR $\left(400 \mathrm{MHz}, \mathrm{CD}_{2} \mathrm{Cl}_{2}\right) \delta=$ $7.27(\mathrm{~m}, 2 \mathrm{H}), 7.08(\mathrm{~m}, 2 \mathrm{H}), 3.73(\mathrm{~s}, 6 \mathrm{H}), 2.16(\mathrm{~s}, 6 \mathrm{H}) .{ }^{11} \mathrm{~B}$ NMR $(128$ $\left.\mathrm{MHz}, \mathrm{CD}_{2} \mathrm{Cl}_{2}\right) \delta=36.4$ (br s), -6.2 (br s). ${ }^{13} \mathrm{C}\left\{{ }^{1} \mathrm{H}\right\}$ NMR $(101 \mathrm{MHz}$, $\left.\mathrm{CD}_{2} \mathrm{Cl}_{2}\right) \delta=149.0,126.5,122.8,112.9,34.3,9.3$.

CatBBCl ${ }_{2}$ IMes (2-IMes) $\mathrm{BCl}_{3} 1 \mathrm{M}$ in hexanes (0.92 mmol, 0.92 $\mathrm{mL})$ was added to a stirred solution of $\mathrm{B}_{2}$ cat $_{2}$ IMes (1-IMes) $(0.92$ $\mathrm{mmol}, 500 \mathrm{mg}$ ) in $20 \mathrm{~mL}$ of hexane and $5 \mathrm{~mL}$ of toluene at $-77^{\circ} \mathrm{C}$. After the addition, the reaction mixture was warmed to room temperature and stirred for $2 \mathrm{~h}$. Afterwards, all volatiles were removed in vacuo. The residue was washed three times with pentane to yield a white solid (356 mg, 77\%). Elemental analysis calc.: $\mathrm{C}_{39} \mathrm{H}_{44} \mathrm{~B}_{2} \mathrm{~N}_{2} \mathrm{O}_{4}: \mathrm{C}$, 64.21; H, 5.59; N, 5.55. Found: C, 64.02; H, 5.59; N, 5.73. ${ }^{1} \mathrm{H}$ NMR $\left(400 \mathrm{MHz}, \mathrm{CD}_{2} \mathrm{Cl}_{2}\right) \delta=7.10(\mathrm{~s}, 2 \mathrm{H}), 7.00(\mathrm{~m}, 2 \mathrm{H}), 6.94(\mathrm{~m}, 2 \mathrm{H}), 6.79$ (m, 4H), $2.19(\mathrm{~s}, 12 \mathrm{H}), 2.09(\mathrm{~m}, 6 \mathrm{H}) .{ }^{11} \mathrm{~B}$ NMR $\left(128 \mathrm{MHz}, \mathrm{CD}_{2} \mathrm{Cl}_{2}\right) \delta$ $=36.3($ br s $),-6.3$ (br s). ${ }^{13} \mathrm{C}\left\{{ }^{1} \mathrm{H}\right\} \mathrm{NMR}\left(101 \mathrm{MHz}, \mathrm{CD}_{2} \mathrm{Cl}_{2}\right) \delta=149.2$, 141.0, 136.1, 133.3, 129.5, 128.9, 124.2, 122.2, 112.2, 21.3, 18.5.

CatBBCl ${ }_{2}$ IDipp (2-IDIPP). $\mathrm{BCl}_{3} 1 \mathrm{M}$ in hexanes $(0.80 \mathrm{mmol}, 0.80$ $\mathrm{mL})$ was added to a stirred solution of $\mathrm{B}_{2} \mathrm{cat}_{2}$ IDipp (1-IDIPP) $(0.80$ $\mathrm{mmol}, 500 \mathrm{mg}$ ) in $20 \mathrm{~mL}$ of hexane and $5 \mathrm{~mL}$ of toluene at $-77^{\circ} \mathrm{C}$. After the addition, the reaction mixture was warmed to room temperature and stirred for $2 \mathrm{~h}$. Afterwards, all volatiles were removed in vacuo. The residue was washed three times with pentane to yield a white solid (384 mg, 81\%). Elemental analysis calc.: $\mathrm{C}_{33} \mathrm{H}_{40} \mathrm{~B}_{2} \mathrm{Cl}_{2} \mathrm{~N}_{2} \mathrm{O}_{2}$ : $\mathrm{C}, 67.27 ; \mathrm{H}, 6.84 ; \mathrm{N}, 4.75$. Found: $\mathrm{C}, 67.01 ; \mathrm{H}, 6.87 ; \mathrm{N}, 5.04 .{ }^{1} \mathrm{H}$ NMR $\left(400 \mathrm{MHz}, \mathrm{CD}_{2} \mathrm{Cl}_{2}\right) \delta=7.16(\mathrm{~m}, 8 \mathrm{H}), 6.90(\mathrm{~s}, 4 \mathrm{H}), 2.76$ (sept, $J=7.0$ $\mathrm{Hz}, 4 \mathrm{H}), 1.45(\mathrm{~d}, J=6.7 \mathrm{~Hz}, 12 \mathrm{H}), 1.11(\mathrm{~d}, J=6.8 \mathrm{~Hz}, 12 \mathrm{H}) .{ }^{11} \mathrm{~B}$ NMR $\left(128 \mathrm{MHz}, \mathrm{CD}_{2} \mathrm{Cl}_{2}\right) \delta=36.6$ (br s), $-6.3($ br s $) .{ }^{13} \mathrm{C}\left\{{ }^{1} \mathrm{H}\right\}$ NMR $(101$ $\left.\mathrm{MHz}, \mathrm{CD}_{2} \mathrm{Cl}_{2}\right) \delta=149.1,146.6,133.4,131.3,125.2,124.2,121.8$, $112.3,29.8,26.3,22.3$.

[CatBBCIIMe(PPh $)$ ][AICl $\mathbf{4}] \mathbf{( 4 )} . \mathrm{PPh}_{3}(0.15 \mathrm{mmol}, 39 \mathrm{mg})$ was added to a stirred solution of catBBCl${ }_{2} \mathrm{IMe}(\mathbf{2}-\mathrm{IMe})(0.15 \mathrm{mmol}, 49$ $\mathrm{mg})$ in $1 \mathrm{~mL}$ of $o$-dcb. After stirring the solution for $30 \mathrm{~min}, \mathrm{AlCl}_{3}(0.15$ mmol, $20 \mathrm{mg}$ ) was added and the reaction mixture was stirred for $3 \mathrm{~h}$. Afterwards, all volatiles were removed in vacuo. The residue was washed three times with pentane to yield a white solid (96 mg, 89\%). Elemental analysis calc.: $\mathrm{C}_{31} \mathrm{H}_{31} \mathrm{AlB}_{2} \mathrm{Cl}_{5} \mathrm{~N}_{2} \mathrm{O}_{2}$ : $\mathrm{C}, 51.68 ; \mathrm{H}, 4.34 ; \mathrm{N}$, 3.89. Found: $\mathrm{C}, 51.33 ; \mathrm{H}, 4.45 ; \mathrm{N}, 4.01 .{ }^{1} \mathrm{H}$ NMR $\left(400 \mathrm{MHz}, \mathrm{CD}_{2} \mathrm{Cl}_{2}\right)$ $\delta=7.73-7.63(\mathrm{~m}, 10 \mathrm{H}), 7.60-7.55(\mathrm{~m}, 5 \mathrm{H}), 7.22(\mathrm{~m}, 2 \mathrm{H}), 7.13(\mathrm{~m}, 2 \mathrm{H})$, $2.93(\mathrm{~s}, 6 \mathrm{H}), 2.17(\mathrm{~s}, 6 \mathrm{H}) .{ }^{11} \mathrm{~B}$ NMR $\left(128 \mathrm{MHz}, \mathrm{CD}_{2} \mathrm{Cl}_{2}\right) \delta=37.7(\mathrm{br}$ s), -14.8 (br s). ${ }^{13} \mathrm{C}\left\{{ }^{1} \mathrm{H}\right\}$ NMR $\left(101 \mathrm{MHz}, \mathrm{CD}_{2} \mathrm{Cl}_{2}\right) \delta=148.1,134.8$ $(\mathrm{d}, J=8.7 \mathrm{~Hz}), 133.9(\mathrm{~d}, J=2.7 \mathrm{~Hz}), 130.3(\mathrm{~d}, J=10.8 \mathrm{~Hz}), 129.7$, 123.8, 123.6, 122.9, 113.3, 34.7, 9.9. ${ }^{31} \mathrm{P}$ NMR $\left(162 \mathrm{MHz}, \mathrm{CD}_{2} \mathrm{Cl}_{2}\right) \delta$ 1.44. ${ }^{27} \mathrm{Al}$ NMR (104 MHz, $\left.\mathrm{CD}_{2} \mathrm{Cl}_{2}\right) \delta 103.8$.

[CatBBCI(IMe)2-DMAP] [B( $\left.\left(\mathbf{C}_{6} \mathbf{F}_{5}\right)_{4}\right]$ ](5). 2-DMAP (0.15 mmol, 19 $\mu \mathrm{L})$ was added to a stirred solution of catBBCl ${ }_{2} \mathrm{IMe}(\mathbf{2}$-IMe $)(0.15$ $\mathrm{mmol}, 49 \mathrm{mg}$ ) in $1 \mathrm{~mL}$ of $o$-dcb. After stirring the solution for $30 \mathrm{~min}$, $\mathrm{K}\left[\mathrm{B}\left(\mathrm{C}_{6} \mathrm{~F}_{5}\right)_{4}\right](0.15 \mathrm{mmol}, 164 \mathrm{mg})$ was added and the reaction mixture was stirred overnight. Afterwards, the reaction mixture was filtered and all volatiles were removed in vacuo. The residue was washed with pentane and benzene to yield a yellow solid $(120 \mathrm{mg}, 73 \%)$. Elemental analysis calc.: $\mathrm{C}_{44} \mathrm{H}_{26} \mathrm{~B}_{3} \mathrm{ClF}_{20} \mathrm{~N}_{2} \mathrm{O}_{2}: \mathrm{C}, 48.46 ; \mathrm{H}, 2.40 ; \mathrm{N}, 5.14$. Found: $\mathrm{C}, 48.17 ; \mathrm{H}, 2.41 ; \mathrm{N}, 5.10 .{ }^{1} \mathrm{H}$ NMR $\left(400 \mathrm{MHz}, \mathrm{CD}_{2} \mathrm{Cl}_{2}\right) \delta=8.75(\mathrm{~d}, J$ $=6.1,1 \mathrm{H}), 8.39(\mathrm{dd}, J=7.6,7.5 \mathrm{~Hz}, 1 \mathrm{H}), 7.74(\mathrm{~m}, 2 \mathrm{H}), 7.09(\mathrm{~m}, 2 \mathrm{H})$, $6.98(\mathrm{~m}, 2 \mathrm{H}), 3.44(\mathrm{~s}, 6 \mathrm{H}), 2.60(\mathrm{~s}, 6 \mathrm{H}), 2.18(\mathrm{~s}, 6 \mathrm{H}) .{ }^{11} \mathrm{~B}$ NMR $(128$ $\mathrm{MHz}, \mathrm{CD}_{2} \mathrm{Cl}_{2}$ ) $\delta=29.9$ (br s), -3.7 (br s), -16.7 (sharp, $\mathrm{B}\left(\mathrm{C}_{6} \mathrm{~F}_{5}\right)_{4}$ ). ${ }^{13} \mathrm{C}\left\{{ }^{1} \mathrm{H}\right\}$ NMR $\left(101 \mathrm{MHz}, \mathrm{CD}_{2} \mathrm{Cl}_{2}\right) \delta=163.2,149.5,148.7(\mathrm{~d}, J=240$ Hz) $147.4,147.3,138.8(\mathrm{~d}, J=245 \mathrm{~Hz}), 136.9(\mathrm{~d}, J=245 \mathrm{~Hz}), 128.4$, 125.7, 122.4, 121.7, 112.1, 46.2, 34.4, 9.4. ${ }^{19} \mathrm{~F}$ NMR $(376 \mathrm{MHz}$, $\left.\mathrm{CD}_{2} \mathrm{Cl}_{2}\right) \delta-132.1$ to $-134.6(\mathrm{~m}),-163.5(\mathrm{t}, J=20.3 \mathrm{~Hz}),-167.1$ to $169.6(\mathrm{~m})$.

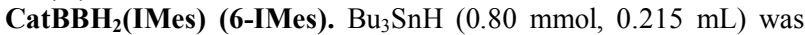
added to a stirred solution of catBBCl $\mathrm{IMes}_{2}$ (2-IMes) $(0.40 \mathrm{mmol}, 200$ $\mathrm{mg})$ and $\mathrm{Na}\left[\mathrm{BAr}{ }^{\mathrm{Cl}}\right](0.04 \mathrm{mmol}, 25 \mathrm{mg})$ in $10 \mathrm{~mL}$ of DCM. After stirring the solution for $1 \mathrm{~h}$, all volatiles were removed in vacuo. The residue was washed three times with pentane to yield a white solid (132 $\mathrm{mg}, 76 \%$ ). An analytically pure sample of 6-IMes could not be obtained as during purification $\mathrm{Na}\left[\mathrm{BArCl}_{4}\right]$ was co-crystallized with 6IMes and could not be separated. ${ }^{1} \mathrm{H}$ NMR $\left(400 \mathrm{MHz}, \mathrm{CD}_{2} \mathrm{Cl}_{2}\right) \delta=7.03$ $(\mathrm{s}, 2 \mathrm{H}), 6.95(\mathrm{~m}, 2 \mathrm{H}), 6.93(\mathrm{~s}, 4 \mathrm{H}), 6.88(\mathrm{~m}, 2 \mathrm{H}), 2.27(\mathrm{~s}, 6 \mathrm{H}), 2.10(\mathrm{~s}$, 12H). ${ }^{11} \mathrm{~B}$ NMR $\left(128 \mathrm{MHz}, \mathrm{CD}_{2} \mathrm{Cl}_{2}\right) \delta=42.4$ (br s), -40.0 (br s). ${ }^{13} \mathrm{C}\left\{{ }^{1} \mathrm{H}\right\}$ NMR $\left(101 \mathrm{MHz}, \mathrm{CD}_{2} \mathrm{Cl}_{2}\right) \delta=149.5,139.7,135.7,135.0$, $129.5,121.5,121.3,111.5,21.4,18.0$. 
CatBBH $_{2}$ IDipp (6-IDIPP). $\mathrm{Bu}_{3} \mathrm{SnH}(0.68 \mathrm{mmol}, 0.183 \mathrm{~mL})$ was added to a stirred solution of catBBCl $\mathrm{IDipp}_{\text {(2-IDIPP) }}(0.34 \mathrm{mmol}$, $200 \mathrm{mg})$ and $\mathrm{NaBArCl}(0.034 \mathrm{mmol}, 21 \mathrm{mg})$ in $10 \mathrm{~mL}$ of DCM. After stirring the solution for $1 \mathrm{~h}$, all volatiles were removed in vacuo. The residue was washed three times with pentane to yield a white solid. (106 mg, 60\%). An analytically pure sample of 6-IMes could not be obtained as during purification $\mathrm{Na}\left[\mathrm{BAr}_{4}{ }_{4}\right]$ was co-crystallized with 6IMes and could not be separated. ${ }^{1} \mathrm{H} \mathrm{NMR}\left(400 \mathrm{MHz}, \mathrm{CD}_{2} \mathrm{Cl}_{2}\right) \delta=7.43$ $(\mathrm{t}, J=7.7 \mathrm{~Hz}, 2 \mathrm{H}), 7.26(\mathrm{~d}, J=7.8 \mathrm{~Hz}, 4 \mathrm{H}), 6.93(\mathrm{~m}, 2 \mathrm{H}), 6.86(\mathrm{~m}$, 2H), 2.73 (sept, $J=6.8 \mathrm{~Hz}, 4 \mathrm{H}), 1.18$ (d, $J=6.9 \mathrm{~Hz}, 12 \mathrm{H}), 1.15$ (d, $J$ $=6.9 \mathrm{~Hz}, 12 \mathrm{H}) .{ }^{11} \mathrm{~B} \mathrm{NMR}\left(128 \mathrm{MHz}, \mathrm{CD}_{2} \mathrm{Cl}_{2}\right) \delta=42.5$ (br s), -39.3 (br s). ${ }^{13} \mathrm{C}\left\{{ }^{1} \mathrm{H}\right\}$ NMR $\left(101 \mathrm{MHz}, \mathrm{CD}_{2} \mathrm{Cl}_{2}\right) \delta=149.62,146.34,134.97$, $130.55,124.51,122.87,121.35,111.66,29.21,25.75,23.01$.

\section{ASSOCIATED CONTENT}

\section{Supporting Information}

The Supporting Information is available free of charge on the ACS Publications website.

Additional experimental details and NMR spectra (PDF)

Coordinates for all calculations (XYZ)

Crystallographic data (CCDC 1840161, 1840162, 1840163, 1840193) (CIF)

\section{AUTHOR INFORMATION}

\section{Corresponding Authors}

* Michael.ingleson@manchester.ac.uk

* h.braunschweig@uni-wuerzburg.de

Key words: Diboron, boronium cations, boron, Lewis acids, electrophiles

\section{ACKNOWLEDGMENTS}

The authors gratefully acknowledge the award of a Marie Cure Fellowship to J.C. (703227 - DIBOR), the University of Manchester and the EPSRC (grant No. EP/K03099X/1 and EP/R001499/1). A. H. thanks the Fonds der Chemischen Industrie for a $\mathrm{PhD}$ fellowship. H.B. thanks the European Research Council for an Advanced Grant under the European Union Horizon 2020 Research and Innovation Program (grant agreement no. 669054). Additional research data supporting this publication are available as supplementary information accompanying this publication.

\section{REFERENCES}

(1) (a) Dewhurst, R. D.; Neeve, E. C.; Braunschweig, H.; Marder, T. B. Chem Commun. 2015, 51, 9594-9607. (b) Neeve, E. C.; Geier, S. J.; Mkhalid, I. A. I.; Westcott, S. A.; Marder, T. B. Chem. Rev. 2016, 116, 9091-9161

(2) (a) Lee, K.; Zhugralin, A. R.; Hoveyda, A. H. J. Am. Chem. Soc. 2009, 131, 7253-7255. (b) Bonet, A.; Gulyás, H.; Fernández, E. Angew. Chem., Int. Ed., 2010, 49, 5130-5134. (c) Bonet, A.; Pubill-Ulldemolins, C.; Bo, C.; Gulyás, H.; Fernández, E. Angew. Chem., Int. Ed., 2011, 50, 7158-7161. (d) Wu, H.; Radomkit, S.; O’Brien, J. M.; Hoveyda, A. H. J. Am. Chem. Soc. 2012, 134, 8277-8285. (e) PubillUlldemolins, C.; Bonet, A.; Bo, C.; Gulyás, H.; Fernández, E. Chem. Eur. J. 2012, 18, 1121-1126. (f) Pietsch, S.; Neeve, E. C.; Apperley, D. C.; Bertermann, R.; Mo, F.; Qiu, D.; Cheung, M. S.; Dang, L.; Wang, J.; Radius, U.; Lin, Z.; Kleeberg, C.; Marder, T. B. Chem. Eur. J. 2015, 21, 7082-7099. (g) Cuenca, A. S.; Shishido, R.; Ito, H., Fernández, E. Chem. Soc. Rev. 2017, 46, 415-430.

(3) (a) Urry, G.; Kartik, T.; Moore, R. E.; Schlesinger, H. I. J. Am. Chem. Soc. 1954, 76, 5293-5298. (b) Timms, P. L.; Ittel, S. D.; Kuck,
M. Inorg. Synth. 1979, 19, 74-78. (c) Morrison, J. A. Chem. Rev. 1991, 91, 35 .

(4) Arrowsmith, M.; Böhnke, J.; Braunschweig, H.; Deißenberger, A.; Dewhurst, R. D.; Ewing, W. C.; Hörl, C.; Mies, J.; Muessig, J. H. Chem. Commun. 2017, 53, 8265-8267.

(5) Katsuma, Y.; Tsukahara, N.; Wu, L.; Lin, Z.; Yamashita, M. Angew. Chem. Int. Ed. 2018, DOI:10.1002/anie.201800878.

(6) (a) Braunschweig, H.; Damme, A.; Dewhurst, R. D.; Kramer, T.; Radacki, K.; Siedler, E.; Trumpp, A.; Wagner, K.; Werner, C. J. Am. Chem. Soc. 2013, 135, 8702-8707. (b) Arnold, A.; Braunschweig, H.; Dewhurst, R. D.; Hupp, F.; Radacki, K.; Trumpp, A. Chem. Eur. J. 2016, 22, 13927-13934.

(7) Prokofjevs, A.; Angew. Chem. Int. Ed. 2015, 54, 13401.

(8) Wang, S. R.; Arrowsmith, M.; Braunschweig, H.; Dewhurst, R. D.; Paprocki, V.; Winner, L. Chem. Commun. 2017, 53, 11945-11947.

(9) (a) Asakawa, H.; Lee, K. H.; Lin, Z.; Yamashita, M. Nature Commun. 2014, 5, 4245. (b) Kojima, C.; Lee, K.-H.; Lin, Z.; Yamashita, M. J. Am. Chem. Soc. 2016, 138, 6662-6669. (c) Katsuma, Y.; Asakawa, H.; Lee, K.-H.; Lin, Z.; Yamashita, M. Organometallics 2016, 35, 2563-2566. (d) Katsuma, Y.; Asakawa, H.; Yamashita, M. Chem. Sci. 2018, 9, 1301-1310.

(10) Zheng, J. Li, Z. H.; Wang, H. Chem. Sci. 2018, 9, 1433-1438.

(11) (a) Litters, S.; Kaifer, E.; Enders, M.; Himmel, H.-J. Nat. Chem. 2013, 5, 1029-1034. (b) Litters, S.; Ganschow, M.; Kaifer, E.; Himmel, H.-J. Eur. J. Inorg. Chem. 2015, 5188-5195. (c) Litters, S.; Kaifer, E.; Himmel, H. -J. Angew. Chem. Int. Ed. 2016, 55, 4345-4347. (d) Litters, S.; Kaifer, E.; Himmel, H.-J. Eur. J. Inorg. Chem. 2016, 4090-4098. (e) Lin, Y.-F.; Chiu, C.-W. Chem Lett. 2017, 46, 913-922.

(12) Pietsch, S.; Paul, U.; Cade, I. A.; Ingleson, M. J.; Radius, U.; Marder, T. B. Chem. Eur. J. 2015, 21, 9018-9021, b) Cade, I. A.; Chau, W. Y.; Vitorica-Yrezabal, I.; Ingleson, M. J. Dalton Trans. 2015, 44, 7506-7511.

(13) (a) Kleeberg, C.; Crawford, A. G.; Batsanov, A. S.; Hodgkinson, P.; Apperley, D. C.; Cheung, M. S.; Lin, Z.; Marder, T. B. J. Org. Chem. 2012, 77, 785-789. (b) Eck, M.; WürtembergerPietsch, S.; Eichhorn, A.; Berthel, J. H. J.; Bertermann, R.; Paul, U. S. D.; Schneider, H.; Friedrich, A.; Kleeberg, C.; Radius, U.; Marder, T. B. Dalton Trans. 2017, 46, 3661-3680.

(14) The synthesis of $\mathrm{BBr}_{3}$ derivatives will be reported in a separate manuscript along with its reduction chemistry.

(15) Cid, J.; Carbó, J. J.; Fernández, E. Chem. Eur. J. 2012, 18, 12794-12802.

(16) Clark, E.; Del Grosso, A.; Ingleson, M. J. Chem. Eur. J. 2013 $19,2462-2466$

(17) Arrowsmith, M.; Braunschweig, H.; Radacki, K.; Thiess, T.; Turkin, A. Chem. Eur. J. 2017, 23, 2179-2184.

(18) Brahmi, M. M.; Monot, J.; Murr, M. D. E.; Curran, D. P.; Fensterbank, L.; Lacôte, E.; Malacria, M. J. Org. Chem., 2010, 75, 6983.

(19) Clark, E.; Ingleson M. J. Angew. Chem. Int. Ed., 2014, 53, 11306.

(20) Gaussian 09, Revision C1, Frisch, M. J.; Trucks, G. W.; Schlegel, H. B.; Scuseria, G. E.; Robb, M. A.; Cheeseman, J. R.; Scalmani, G.; Barone, V.; Mennucci, B.; Petersson, G. A.; Nakatsuji, H.; Caricato, M.; Li, X.; Hratchian, H. P.; Izmaylov, A. F.; Bloino, J.; Zheng, G.; Sonnenberg, J. L.; Hada, M.; Ehara, M.; Toyota, K.; Fukuda, R.; Hasegawa, J.; Ishida, M.; Nakajima, T.; Honda, Y.; Kitao, O.; Nakai, H.; Vreven, T.; Montgomery, Jr., J. A.; Peralta, J. E.; Ogliaro, F.; Bearpark, M.; Heyd, J. J.; Brothers, E.; Kudin, K. N.; Staroverov, V. N.; Kobayashi, R.; Normand, J.; Raghavachari, K.; Rendell, A.; Burant, J. C.; Iyengar, S. S.; Tomasi, J.; Cossi, M.; Rega, N.; Millam, J. M.; Klene, M.; Knox, J. E.; Cross, J. B.; Bakken, V.; Adamo, C.; Jaramillo, J.; Gomperts, R.; Stratmann, R. E.; Yazyev, O.; Austin, A. J.; Cammi, R.; Pomelli, C.; Ochterski, J. W.; Martin, R. L.; Morokuma, K.; Zakrzewski, V. G.; Voth, G. A.; Salvador, P.; Dannenberg, J. J.; Dapprich, S.; Daniels, A. D.; Farkas, Ö.; Foresman, J. B.; Ortiz, J. V.; Cioslowski, J.; Fox, D. J. Gaussian, Inc., Wallingford CT, 2009. 